\title{
The ESTRO Breur Lecture 2009. From population to voxel-based radiotherapy: Exploiting intra-tumour and intra-organ heterogeneity for advanced treatment of non-small cell lung cancer
}

Citation for published version (APA):

Lambin, P., Petit, S. F., Aerts, H. J. W. L., van Elmpt, W. J. C., Oberije, C. J. G., Starmans, M. H. W., van Stiphout, R. G. P. M., van Dongen, G. A. M. S., Muylle, K., Flamen, P., Dekker, A. L. A. J., \& De Ruysscher, D. (2010). The ESTRO Breur Lecture 2009. From population to voxel-based radiotherapy: Exploiting intra-tumour and intra-organ heterogeneity for advanced treatment of non-small cell lung cancer. Radiotherapy and Oncology, 96(2), 145-152. https://doi.org/10.1016/j.radonc.2010.07.001

Document status and date:

Published: 01/08/2010

DOI:

10.1016/j.radonc.2010.07.001

Document Version:

Publisher's PDF, also known as Version of record

Document license:

Taverne

Please check the document version of this publication:

- A submitted manuscript is the version of the article upon submission and before peer-review. There can be important differences between the submitted version and the official published version of record. People interested in the research are advised to contact the author for the final version of the publication, or visit the DOI to the publisher's website.

- The final author version and the galley proof are versions of the publication after peer review.

- The final published version features the final layout of the paper including the volume, issue and page numbers.

Link to publication

\footnotetext{
General rights rights.

- You may freely distribute the URL identifying the publication in the public portal. please follow below link for the End User Agreement:

www.umlib.nl/taverne-license

Take down policy

If you believe that this document breaches copyright please contact us at:

repository@maastrichtuniversity.nl

providing details and we will investigate your claim.
}

Copyright and moral rights for the publications made accessible in the public portal are retained by the authors and/or other copyright owners and it is a condition of accessing publications that users recognise and abide by the legal requirements associated with these

- Users may download and print one copy of any publication from the public portal for the purpose of private study or research.

- You may not further distribute the material or use it for any profit-making activity or commercial gain

If the publication is distributed under the terms of Article 25fa of the Dutch Copyright Act, indicated by the "Taverne" license above,

Download date: 26 Apr. 2023 
Breur Lecture 2009

\title{
The ESTRO Breur Lecture 2009. From population to voxel-based radiotherapy: Exploiting intra-tumour and intra-organ heterogeneity for advanced treatment of non-small cell lung cancer ${ }^{\text {is }}$
}

\author{
Philippe Lambin ${ }^{\mathrm{a}, *, 1}$, Steven F. Petit ${ }^{\mathrm{a}, 1}$, Hugo J.W.L. Aerts ${ }^{\mathrm{a}}$, Wouter J.C. van Elmpt ${ }^{\mathrm{a}}$, Cary J.G. Oberije ${ }^{\mathrm{a}}$, \\ Maud H.W. Starmans ${ }^{a}$, Ruud G.P.M. van Stiphout ${ }^{a}$, Guus A.M.S. van Dongen ${ }^{\text {b,c }}$, Kristoff Muylle ${ }^{\mathrm{d}}$, \\ Patrick Flamen ${ }^{\mathrm{d}}$, André L.A.J. Dekker ${ }^{\mathrm{a}}$, Dirk De Ruysscher ${ }^{\mathrm{a}}$ \\ ${ }^{a}$ Department of Radiation Oncology (MAASTRO), GROW-School for Oncology and Developmental Biology, Maastricht University Medical Centre, The Netherlands; ${ }^{\mathrm{b}}$ Department

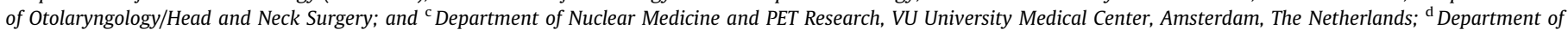 \\ Nuclear Medicine, Institut Jules Bordet, Université Libre De Bruxelles (ULB), Brussels, Belgium
}

\section{A R T I C L E I N F O}

\section{Article history:}

Received 23 March 2010

Received in revised form 7 July 2010

Accepted 7 July 2010

\section{Keywords:}

Heterogeneity

Non-small cell lung cancer (NSCLC)

Fluorodeoxyglucose (FDG)

Dose-painting

Dose redistribution

Biological dose optimization

\begin{abstract}
A B S T R A C T
Evidence is accumulating that radiotherapy of non-small cell lung cancer patients can be optimized by escalating the tumour dose until the normal tissue tolerances are met. To further improve the therapeutic ratio between tumour control probability and the risk of normal tissue complications, we firstly need to exploit inter patient variation. This variation arises, e.g. from differences in tumour shape and size, lung function and genetic factors. Secondly improvement is achieved by taking into account intra-tumour and intra-organ heterogeneity derived from molecular and functional imaging. Additional radiation dose must be delivered to those parts of the tumour that need it the most, e.g. because of increased radio-resistance or reduced therapeutic drug uptake, and away from regions inside the lung that are most prone to complication. As the delivery of these treatments plans is very sensitive for geometrical uncertainties, probabilistic treatment planning is needed to generate robust treatment plans. The administration of these complicated dose distributions requires a quality assurance procedure that can evaluate the treatment delivery and, if necessary, adapt the treatment plan during radiotherapy.
\end{abstract}

(c) 2010 Elsevier Ireland Ltd. All rights reserved. Radiotherapy and Oncology 96 (2010) 145-152
Over the past decades we have witnessed an unprecedented increase in our basic understanding of cancer at the molecular level, experienced a huge improvement in medical technology and have gained access to an ever increasing amount of data on cancer. As a consequence, modern medical diagnostic systems confront doctors with a flood of clinical, anatomical, molecular en genetic data and an increasing number of therapeutic strategies. It is a huge challenge to integrate all available information and select the best, individualized treatment for each patient that best fits his/her needs. This is relevant because amongst patients with the same tumour stage there is a large variation with respect to response to systemic treatment and radiotherapy for both the tumour as well as the healthy organs. Although biologically effective dose levels of at least $100 \mathrm{~Gy}$ are required to achieve local tumour control rates

\footnotetext{
Data presented during the Breur Lecture in Berlin (ECCO meeting 2009).

* Corresponding author. Address: Department of Radiation Oncology (MAASTRO Clinic), GROW - School for Oncology and Developmental Biology, Maastricht University Medical Centre, Dr. Tanslaan 12, NL-6229 ET Maastricht, The Netherlands.

E-mail address: philippe.lambin@maastro.nl (P. Lambin).

1 These authors contributed equally to this work.
}

of $90 \%$ or more $[1,2]$, in most radiotherapy departments it is a common practice to prescribe the same dose to all patients, e.g. $66 \mathrm{~Gy}$ delivered in 33 fractions over about 7 weeks, which is equivalent to a biological dose of less than $51 \mathrm{~Gy}$ [3]. Higher local control rates may be achieved if the dose would be escalated to the highest dose that can be delivered to the tumour at an acceptable normal tissue complication level for each patient. This idea was exploited recently in a prospective single-arm dose-escalation study where stages I-III, non-operable NSCLC patients were treated iso-toxically with sequential chemo-radiation [4]. The radiation dose to the tumour was escalated from $54 \mathrm{~Gy}$ to a maximum of $79.2 \mathrm{~Gy}$, delivered in twice-daily fractions of $1.8 \mathrm{~Gy}$ to achieve an overall treatment time of less than 5 weeks, until a fixed mean lung dose (MLD) was reached that depended on the lung function of the patient. Since patients with a reduced lung function are more likely to have complications, the allowed MLD for these patients (12 or $15 \mathrm{~Gy}$ ) was lower than for patients with a good lung function (19 Gy). The 2-years survival of the patients included in this trial was $45 \%$, which is comparable to patients treated with concurrent chemo-radiotherapy. This indicates how the balance between toxicity and tumour control could be used in the clinic to improve the treatment and it underlines the importance of individualized 


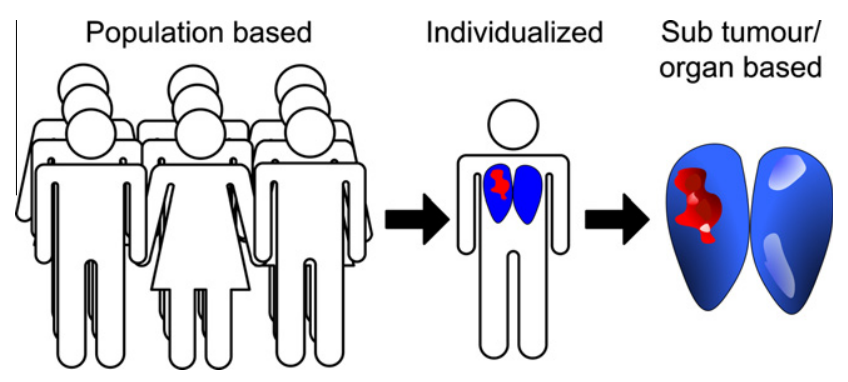

Fig. 1. Schematic scheme illustrating how the treatment of lung cancer with radiotherapy evolves from population based to individualized, to strategies that take into account differences in radio-sensitivity within the tumour and lungs. With individualized radiotherapy the tumour and lungs are considered as homogeneous organs. The next step is to consider intra-tumour and lung heterogeneity. Red and blue indicate tumour and lung, respectively. See power point version of the figure in the Supplementary data.

radiotherapy. "One size fits all" will no longer be an option for the treatment of lung cancer in the upcoming era.

To further refine the selection of the best treatment based on the balance between probability of cure and complications, accurate models must be used to predict the therapeutic ratio of a treatment for individual patients, i.e. the ratio between the probability of tumour control and the risk on normal tissue complications. Validated models can then be incorporated into a decision support system (DSS) that presents the different treatment options with the expected therapeutic ratios to the physician. The simplest and most intuitive example of a decision support tool is a nomogram. Nomograms are graphical representations of prediction models that are used to add up different risk factors and calculate the probability of a certain outcome [5-8]. More advanced DSSs can make predictions about more than one outcome measure, e.g. normal tissue toxicity, local tumour control, distance metastasis and quality of adjusted life year (QALY) expectancy [9]. Developing an accurate DSS is very challenging because it requires a huge amount of data from sufficient patients that have been treated with different treatment regimes.

DSSs can be used to exploit inter patient heterogeneity by selecting for each patient individually the treatment with the best therapeutic ratio. However, even if a DSS would be available that could perfectly exploit inter patient heterogeneity, for a large number of patients the tumour dose simply cannot be elevated enough to obtain a high tumour control probability without accepting severe complications $[10,11]$. Further improvement of the therapeutic ratio between tumour control probability (TCP) and normal tissue complication probability (NTCP) could be achieved by exploiting intra-tumour and intra-organ heterogeneity. Both tumours and organs are known to be heterogeneous structures with regions of different radio-sensitivity, functionality and drug uptake. In contrast to other treatment modalities, radiotherapy can be used to exploit this spatial heterogeneity. Guiding dose towards the most radio-resistant part of the tumour or to regions with a low therapeutic drug uptake and simultaneously away from the sensitive, functional or complication prone parts of the lungs can lead to higher control probability without increasing the complication probability. The therapeutic ratio can thus be improved by exploiting tumour and organ heterogeneity. Fig. 1 illustrates how radiotherapy evolves from population to voxel based.

\section{Tumour heterogeneity}

A malignant tumour is not a homogeneous mass, but is composed of regions that differ in tumour cell density, normal tissue involvement, vasculature, hypoxia, proliferation, gene expression and drug uptake [12]. This heterogeneity within the tumour results in large spatial differences in response to radiotherapy, chemotherapy, or new targeted agents. The discovery of intra-tumour heterogeneity opens new therapeutic possibilities for individualized patient treatment. Today, radiation is given to the tumour at a more or less homogeneous dose (international guidelines from the ICRU 50 report state that the whole tumour should receive 95-107\% of the prescribed dose). Cells with an increased resistance to radiation thus receive the same dose as the more sensitive cells, resulting in a "waste" of dose to the sensitive areas and to a noneffective dose to the resistant parts of a tumour. If the total radiation dose cannot further be escalated because it is restricted by normal tissue tolerance, dose redistribution with a higher dose to resistant and a lower dose to sensitive areas within the tumour has a theoretical advantage. If this tumour heterogeneity can be assessed with volumetric (3D) or even time-resolved (4D) imaging methods [13-15] it is possible to design a therapy that targets the most resistant regions of the tumour, by redistributing or boosting the radiation dose to these regions. A number of theoretical concepts exploring the therapeutic possibilities of intra-tumour heterogeneity have been published [12,16-23]. Many research groups considered giving a higher dose to some parts of the tumour based on some expectation of radio-resistance in that region, i.e. "dose-painting”. Others investigated dose-painting-bynumbers were each tumour voxel or subvolume has an individual target dose depending on images of tracer uptake. The major challenge remains how to determine to which tumour regions how much dose should be administered and by which techniques this can be achieved.

Three different but complementary approaches are outlined below to select tumour regions that may benefit from an additional boost dose.

\section{Dose-painting based on biological characteristics}

The first approach is to determine the radio-sensitivity of the areas with different biological characteristics such as hypoxia, proliferation and clonogen cell density. Hypoxia, as a result of rapid

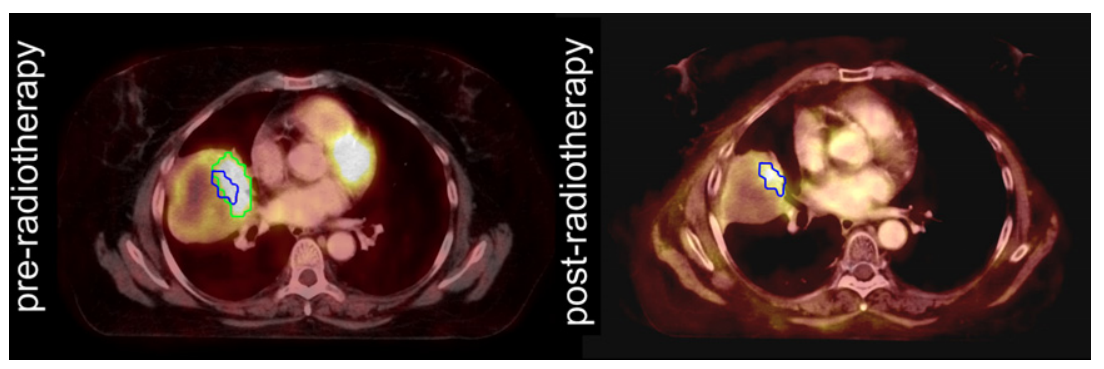

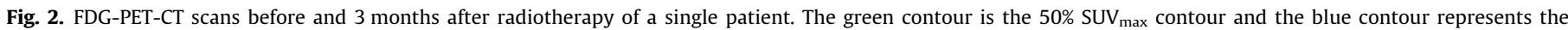

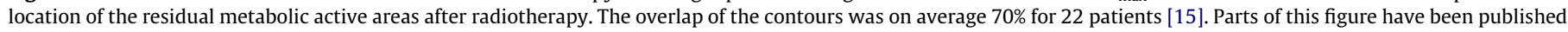
previously in reference [15]. See power point version of the figure in the Supplementary data. 
cellular expansion and/or insufficient tumour angiogenesis [24], is an important biological property in solid tumours that can accelerate malignant progression and metastatic potential of primary carcinomas and also lead to increased resistance to cancer therapies [25-28]. There is therefore a clear rationale to administer an additional radiation dose to hypoxic regions of the tumour. Non-invasive imaging techniques have been proposed to measure oxygenation levels in solid tumours. One such technique involves PET using radiolabelled 2-nitroimidazoles, like $\left[{ }^{18} \mathrm{~F}\right]$ fluoromisonidazole ([ ${ }^{18}$ F]FMISO) [29-33].

\section{Dose-painting based on topography of relapse}

The second strategy is based on images of metabolic activity. Tumour regions with high metabolic activity have been shown to correlate with the site of tumour relapse after radiotherapy. Laprie et al. [34] demonstrated this in Glioblastoma by measuring the choline (Cho)/ $\mathrm{N}$-acetyl-aspartate (NAA) ratio before radiotherapy. Other groups found similar results looking at the metabolic residual areas after radiotherapy using 18-fluorodeoxyglucose (FDG)PET-CT scans. In NSCLC patients it was shown that the residual metabolic active areas after treatment could be identified with the high FDG-uptake areas before treatment [15,35]. Fig. 2 shows an example of the pre- and post-treatment FDG-PET-CT scan of a patient that had residual metabolic activity after therapy [15]. These 28 patients had a significantly worse overall survival (hazard ratio of 2.9) than the 27 patients without residual metabolic activity after therapy (95\% confidence interval: $1.4-6.0 ; p=0.002$ ). In a separate paper it has been shown that the location of metabolically active areas remains stable during therapy [36]. These observations suggest that high FDG-uptake areas within the tumour may be a potential target for dose-painting. This rationale has also been supported by animal experiments [37]. Studies are now needed to correlate the heterogeneity in FDG uptake with pathological features [38]. Currently the hypothesis that high FDG-uptake regions are more radio-resistant than low FDG-uptake regions is tested in a two-arm randomized phase II trial in the Netherlands. (NCT01024829: Dose-escalation by boosting radiation dose in stage II and III non-small cell lung cancer (NSCLC): a phase II trial (BTV Boost), (http://clinicaltrials.gov/ct2/show/NCT01024829).) Patients in arm A will receive radiotherapy (66 Gy) in 24 fractions of $2.75 \mathrm{~Gy}$ with an integrated boost to the primary tumour as a whole. Patients in arm B receive radiotherapy (66 Gy) in 24 fractions of $2.75 \mathrm{~Gy}$ with an integrated boost to the $50 \% \mathrm{SUV}_{\max }$ area of the primary tumour. The size of the boost dose is determined by the normal tissue constraints and therefore the mean PTV dose will be approximately equal in both the arms.

An alternative strategy to escalate dose based on FDG uptake is by reassessing the tumour volume after the first weeks of radiotherapy using FDG-PET-CT scans and replan if the tumour decreased in size. However this allows only a modest improvement in the context of dose-escalation [39], which confirms the need to consider intra-tumour heterogeneity for dose-escalation.

\section{Dose-painting based on receptor imaging}

A third method to determine which tumour regions must receive an additional dose is by non-invasively imaging the volumetric uptake of labelled drugs, in particular monoclonal antibodies (mAb), inside the tumour. Systemic treatment, chemotherapy or targeted drugs, in combination with radiotherapy play a pivotal role in the treatment of various solid cancers. Systemic treatments are still administered based on the principle of "administered dose", the equivalent of skin dose in radiotherapy. Introduction of immunoPET, the combination of PET with mAbs combines the high sensitivity and resolution of a PET camera with the specificity of a mAb for
18F-fluorodeoxyglucose

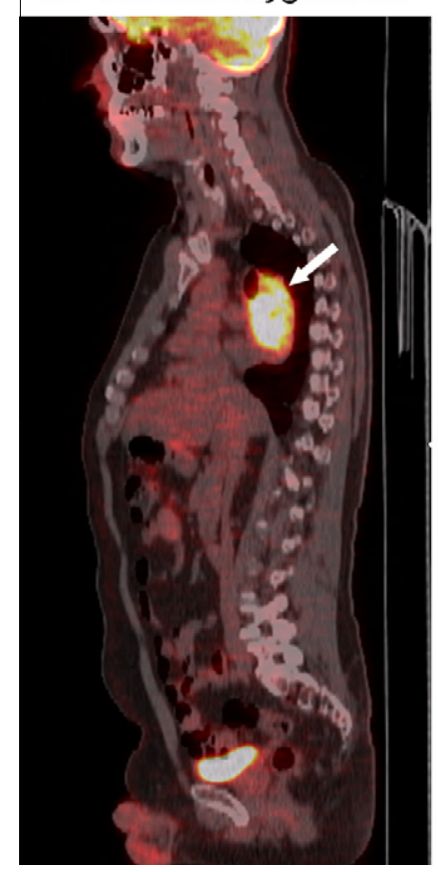

$89 Z$ r-rituximab

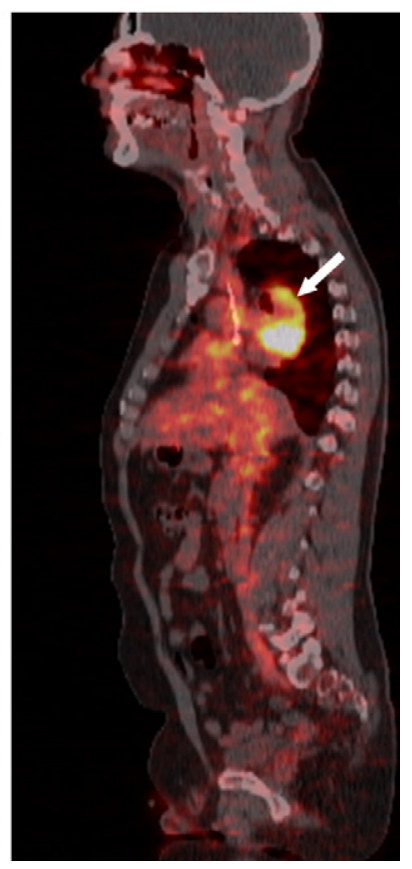

Fig. 3. Comparison of an FDG-PET-CT scan (left) and an ${ }^{89} \mathrm{Zr}$-rituximab PET-CT scan (right) in a patient with relapsed follicular non-Hodgkin's lymphoma. The bottom part of the tumour shows significant higher rituximab uptake than the upper part. See power point version of the figure in the Supplementary data.

tumour specific antigens. The ability to measure the expression of these receptors is promising for selecting patients for targeted therapy. We know from various preclinical studies that not only the receptor expression, but also the absorption of therapeutic drugs is often not homogeneous. Also a disparity between receptor levels and drug uptake has been reported, i.e. a tumour with high receptor levels can report lower uptake than tumours with lower receptor levels. This indicates that also reachability of tumour tissue by large $\mathrm{mAbs}$ is an important factor [40]. Preliminary unpublished data suggest that immuno-PET with ${ }^{89}$ Zirconium labelled rituximab is more accurate than ${ }^{18}$ FDG-PET to depict viable lymphoma in patients with relapsed CD20+ B-cell non-Hodgkin's lymphoma and that the uptake of rituximab can be very heterogeneous throughout the tumour (Fig. 3) [41]. Besides the inherent heterogeneity of antigenexpression in the tumour, tumour regions with low therapeutic drug uptake can also reflect the loss of receptor-expression in clonogens during the course of disease, saturation of receptors due to previous administrations of the drug or the presence of intra-tumoural necrotic or inflammatory tissue. Although still hypothetical, receptor imaging and drug uptake imaging with PET could be an interesting new approach for identifying tumour regions that might benefit from an additional boost.

\section{How much dose should be redistributed?}

It is challenging to define which tumour subregions are suitable candidates for an additional dose. An even more difficult question is how much dose should be redistributed. Different strategies are possible. If biological images can be calibrated to, e.g. partial oxygen pressure, cell density or proliferation, the linear quadratic model of cell survival, or another radiobiological alternative, can be used to determine how much dose should be redistributed $[17,20,28,42,43]$. It should be noted that such a calibration from image intensity to a biological property is a huge challenge and previous studies that applied this approach have relied on qualitative correlations instead of on quantitative relations. An alternative 
strategy is to start treating patients with a fixed, additional boost to a subregion of the tumour and analyze the patterns of relapse after treatment. If the relapse occurs in the boost region, more dose should have been redistributed. If it occurs outside the boost regions, too much dose was redistributed. After the first cohort has been treated and evaluated the boost dose to a new cohort of patients can be refined using the data of the first cohort. By repeating this procedure the optimal boost dose can be determined. This is a very pragmatic approach but it requires data from a large number of patients that have been treated with a boost dose and 3D dosimetry (see Section 'Dose delivery verification') to determine the delivered dose distribution in every subvolume of the tumour for evaluating the patterns of relapse. This procedure has been proposed in a recent publication where it was applied to patients treated with a flat tumour dose ranging between 45 and 79 Gy [23]. Within the coming years data will become available from patients who have been treated with a boost dose to subregions of the tumour

\section{Organ heterogeneity: the example of lung}

Not only tumours but also healthy organs can be heterogeneous in function and sensitivity for complications. However, at present models presume that all parts of an organ have the same functional capacity, i.e. every subvolume has the same function and contributes equally to the global organ function. This is certainly not correct for lungs [44]. Gas diffusion only occurs in the alveoli and there is a large heterogeneity in the functional areas of the lungs because of differences in ventilation and perfusion. In the lungs of patients with lung diseases, such as COPD and lung emphysema, this heterogeneity is even larger. Lung cancer patients often have large non-functional air pockets in the lung (bullae) and sites of inflammation that might be more susceptible to radiation damage. It is expected that a radiation dose to the bullae is less harmful for the patient than dose to regions that contribute most to the lung function.

Different imaging techniques can be used to acquire information about functional and non-functional lung tissue and inflammation. Magnetic resonance imaging (MRI) is a powerful tool for the static and dynamic imaging of many organs including the lungs [45]. Many attempts have been made to visualize local ventilation using the inhalation of hyperpolarized gases or gadolinium aerosol responding to MRI. Groups have shown that mathematical processing of data derived from serial MRI scans during the respiratory cycle produces good quality images of local ventilation without any contrast agent. In patient investigations good correlations were seen between pulmonary function tests and MR ventilation measurements [46]. The ventilation images can be used for intensity modulated radiotherapy (IMRT) planning strategies to spare the well ventilated lung regions [47].

$\mathrm{CT}$ is another technique that has been used in a research setting to obtain ventilation images of the lungs. According to Simon the Hounsfield unit of a voxel in the lung depends linearly on the fractional volume of air in that voxel [48]. The difference in the amount of air in a voxel between inspiration and expiration is a measure of the ventilation [49]. Large variations in ventilation have been observed between different regions of the lung [50]. Since the ventilation measurements are done with the CT scan used for treatment planning the ventilation maps can easily be imported into the treatment planning system and used for treatment planning to limit the radiation dose to functional regions [51].

Together with ventilation, adequate perfusion is needed for sufficient gas exchange in the lungs. Patients with NSCLC often have inhomogeneous perfusion in the lung that can be caused by bullous disease, atelectase and infiltration by the tumour. Radiation can have two separate effects on lung perfusion. On one hand radi-

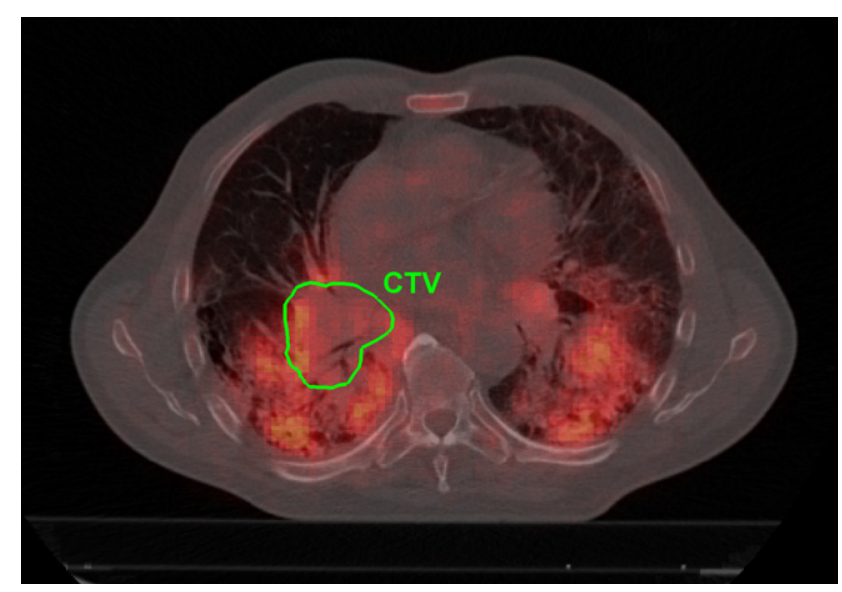

Fig. 4. Illustration of a patient with high FDG uptake in the lungs before radiotherapy. The clinical target volume (CTV) is shown in green. A recent study showed that a large overlap between voxels in the lung with a high FDG uptake and the dose distribution was a risk factor for radiation induced lung toxicity. This finding let us hypothesize that by shielding these high FDG-uptake regions the risk may be decreased [60]. See power point version of the figure in the Supplementary data.

ation damage to well-perfused lung regions can decrease the perfusion. On the other hand tumour regression caused by radiation may cause an increase in perfusion in poorly-perfused lung regions close to the tumour [52]. Also the stiff scar tissue surrounding the bullae can be damaged or decreased by radiation, leading to more perfusion and a local increase in elasticity of the lung tissue yielding more ventilation. There is thus a clear rationale for guiding dose towards poorly-perfused and away from well-perfused lung regions. Perfusion can be measured in 3D using single photon emission computed tomography (SPECT) scanners with an ${ }^{99 m} \mathrm{Tc}$ labelled macro-aggregated albumin [53,54]. Different groups have shown the technical feasibility of incorporating these 3D perfusion maps for treatment planning to decrease the dose to functional lung regions [54-56].

Apart from assessing the contribution of different lung regions to the lung function, imaging techniques can also be used to identify parts of the lung that may be more susceptible for radiation damage. An increased uptake of FDG has already been associated with a number of inflammatory, non-malignant disorders [57]. Also a high FDG uptake in the lungs before treatment and an increase of FDG in the lungs during treatment have been associated with an increased risk on radiation induced lung toxicity (RILT) [58-60]. Only a dose of a few gray to the high FDG-uptake regions increased the risk of RILT [60] (Fig. 4). These results suggest that the lung toxicity can be avoided by shielding regions with high FDG uptake from the radiation fields.

\section{Treatment planning incorporating tumour and organ heterogeneity and geometrical uncertainties}

The technical feasibility of treatment planning with multiple dose prescription levels to the tumour based on biological images has been demonstrated by different groups [17,19-22,43,61-64]. Dose prescriptions ranged from 2 dose levels to a dose distribution that varied continuously based on tracer uptake. Also different groups showed how 3D lung perfusion and/or ventilation maps can be used as input for conformal and IMRT treatment planning to limit the dose to well ventilated/perfused tissue $[47,51,53-$ $56,65,66]$. Das et al. combined information on both tumour (measured with FDG) and lung heterogeneity (perfusion measured with SPECT) in one dose optimization algorithm [67]. 
These studies did not address how to take into account the uncertainty in delivered dose that arises from positioning errors, organ motion and deformations affiliated with fractionated radiotherapy, when administering a dose distribution with multiple dose levels to the tumour. In current radiotherapy practice, with a homogeneous prescription dose to the tumour, these uncertainties are taken into account by the safety margin applied to the delineated gross tumour volume. The reason that the margin approach works, is that tumours are assumed to be homogeneous and that thus a uniform dose distribution is the best way to treat a tumour. As uncertainties in dose delivery occur mostly around dose gradients, the dose uncertainty in a uniform dose distribution is located at the edges of the tumour/uniform dose area. With the margin approach this is exactly the area where the safety margin is applied. However, in the case of a heterogeneous tumour treated with multiple dose levels (e.g. dose-painting), the geometric uncertainties during fractionated treatment and gradients between dose levels result in dose delivery uncertainties, occurring within the tumour. To account for these uncertainties with a margin would require applying a margin for each of the heterogeneous zones or even for each voxel within the tumour. Also the size of the margin would depend on the dose gradient (i.e. a large dose gradient requires a large margin) between the zones and would thus be a result of the planned dose rather than an input for the planning process. The margins approach thus becomes problematic when multiple dose levels need to be prescribed to different regions of a single tumour.

The solution is to incorporate the uncertainties that give rise to the margin directly into the treatment planning system and use them in the treatment plan optimization process. Different groups have shown how probabilistic distributions of systematic and ran- dom positioning error and breathing motion can be incorporated directly into the treatment optimization $[68,69]$. These methods are usually demonstrated with a homogeneous dose prescription. If little information is available about the probability distributions of the uncertain variables, which is in general the case, the difference between a conventional margin based dose distribution and a probabilistic planning dose distribution is small in case of a homogeneous prescribed tumour dose. However, when multiple dose levels within the tumour are prescribed, this probabilistic planning is the method of choice to generate a dose distribution that is more robust to geometrical uncertainties.

\section{Dose delivery verification}

The delivery of complicated, heterogeneous dose distributions with very high dose levels to small target volumes requires steep dose gradients and small multi-leaf collimator (MLC) shaped segments. As a consequence, small changes in patient anatomy or MLC configuration can result in large deviations from the planned dose distribution. Therefore precise geometric and dosimetric verification is of utmost importance to ensure correct planning and delivery for these advanced and complex types of treatment. The state of the art for dose verification are quality assurance procedures using electronic portal imaging devices (EPID) [70]. EPID dosimetry can be used as a QA procedure prior to treatment by comparing the predicted and measured dose of the non-attenuated beam at the EPID plane in 2D. EPID dosimetry can also be used to verify the delivered dose during treatment by comparing the predicted and measured dose of the attenuated beams that exit the patient. 2D EPID dosimetry is already routinely used in a number

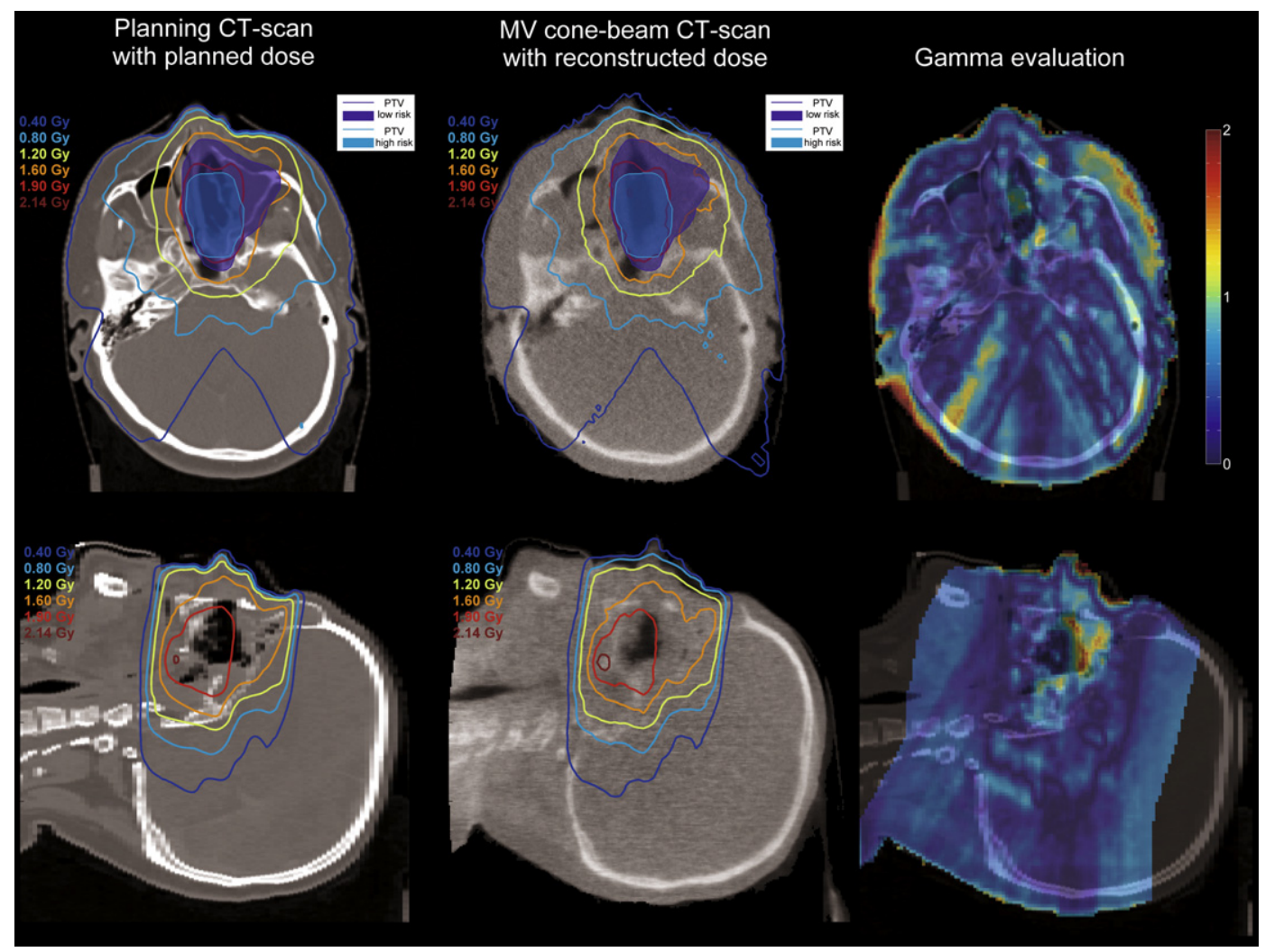

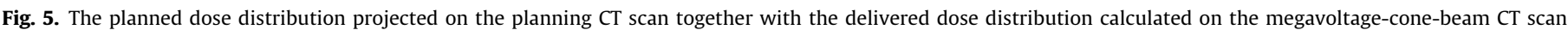

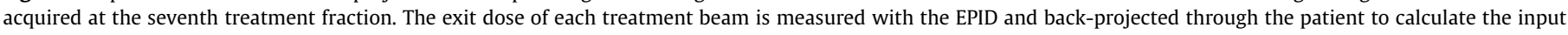

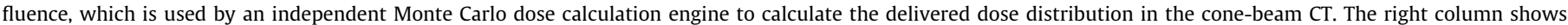

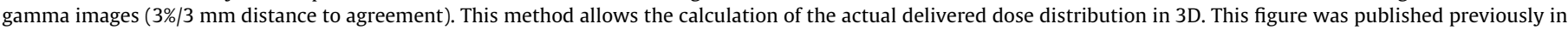
reference [82]. See power point version of the figure in the Supplementary data. 
of clinics and the first commercial solutions are becoming available [71-74]. Although 2D EPID dosimetry is a perfect tool to asses if differences have occurred between the planned and delivered dose distribution, it is not always straightforward to interpret the effect of differences in terms of the dose to the organs and target [71]. This becomes even more complicated when a boost dose is delivered to a subregion of the tumour. A method better suited for the QA of these advanced treatments is 3D EPID in vivo dosimetry [75-82]. The treatment beams delivered are captured behind the patient with an EPID and back-projected through a 3D image of the patient acquired moments before or after each treatment session. The volumetric images can be obtained with cone-beam CT, helical CT or using an in-room diagnostic CT-scanner. The absorbed dose can then be estimated in every voxel of the 3D image. 3D EPID in vivo dosimetry is currently the only method capable of providing the full delivered dose distribution in 3D. It can be fully automated and does not require additional machine time. Fig. 5 shows an example of the planned and delivered dose in a head-and-neck patient. In our opinion this is the method of choice for the verification and QA of treatment plans with different target dose levels to a single tumour.

Another strength of 3D EPID in vivo dosimetry is the ability to provide the feedback needed for plan adaptation, as discussed in the next section, and to evaluate the treatment. As mentioned in Section 'Tumour heterogeneity', data of patients enrolled in studies where different parts of the tumour are irradiated with different dose levels, are needed to further refine dose response relations. For these provide unique information of the response of parts of the tumour with different biological characteristics to different dose levels. For this purpose it is crucial to know very precisely the delivered dose in each part of the tumour and therefore 3D EPID in vivo dosimetry is a prerequisite.

\section{Plan adaptation}

Quality assurance using 3D dose delivery verification is not only needed to guarantee that the treatment is delivered as planned. If during therapy it becomes clear that the treatment plan needs to be adapted, the total delivered dose distribution up to that point in time needs to be known and used in the treatment adaptation strategy to ensure that the new plan compensates for the deviations between the desired and delivered dose distribution. Reasons for treatment plan adaptation can be either anatomical or functional (biology) related.

Changes in anatomy can be caused by weight loss or gain, tumour shrinkage or growth and a shift in tumour or organ position [83-86]. These changes can be detected with the in-room imaging techniques used for patient positioning such as cone-beam CT imaging, without additional burden to the patient and limited workload for the medical team. The appropriate strategy for treatment plan adaptation depends on the type and the timing of observed anatomical changes [87]. Ideally, if unacceptable dosimetric deviations are observed, a new treatment plan must be generated before the next treatment fraction with an updated dose delivery compensating for the nonoptimal delivered dose distribution. Also online strategies may be considered, where the treatment plan is adapted on a daily basis while the patient is on the treatment couch $[88,89]$, but due to computational power and logistic limitations, the clinical introduction of these methods is challenging.

Functional or biological changes not only include alteration in normal tissues, e.g. perfusion, ventilation and atelectases in the lungs, but also for the target volumes, e.g. changes in size, shape and location of the radio-resistant tumour regions. These changes usually cannot be detected with in-room imaging, but additional CT, PET, SPECT or MRI scans are needed. In a prospective study with
23 NSCLC patients, it was shown that the metabolically active regions remained at the same location throughout the course of therapy [36]. For hypoxia, however, which can be chronic or acute, larger differences might occur between scans at different timepoints. In contrast to anatomical changes, it is less obvious how to adapt the treatment plan if the distribution of the biological parameter of interest has changed.

The treatment plan can also be adapted as a result of changes in the normal tissue. Patients with a high increase in FDG uptake during or after therapy have an increased risk of radiation induced lung toxicity [58,59]. If in the first 2 weeks of treatment a strong increase in uptake in the lungs is shown, it might be necessary to reduce the overall dose to the lungs and tumour, to avoid severe complications. On the other hand, no increase of FDG uptake in the lungs could suggest that the total radiation dose to the tumour can be increased without an elevated risk of complications.

\section{Conclusions}

We hypothesize that in the near future decision support systems will be used to select for each patient individually the treatment with the best balance between probability of cure and complications based on inter patient heterogeneity. Apart from inter patient heterogeneity, intra patient heterogeneity could be exploited to further optimize the therapeutic ratio. The dose to complication prone regions of the lungs can be reduced and additional dose can be delivered towards the parts of the tumour that need it the most, for instance because of limited therapeutic drug uptake. The planning of these dose distributions requires that geometrical uncertainties, that are normally included in a treatment planning margin, are directly incorporated into a treatment planning system and used for treatment plan optimization to obtain robust treatment plans. For the quality assurance of these complicated dose distributions 3D EPID in vivo dosimetry is needed to calculate the delivered dose distributions, evaluate them, and if needed, use them for treatment plan adaptation. In short, both inter and intra patient heterogeneity may be exploited to improve the treatment of NSCLC patients with radiotherapy.

\section{Conflict of interest}

We are not aware of any actual or potential conflicts of interest.

\section{Acknowledgments}

This study was performed within the framework of CTMM, the Center for Translational Molecular Medicine (www.ctmm.nl), project AIRFORCE number 030-103.

This work has been funded with the support of the METOXIA project no. 222741 under the 7th Research Framework Programme of the European Union.

\section{Appendix A. Supplementary data}

Supplementary data associated with this article can be found, in the online version, at doi:10.1016/j.radonc.2010.07.001.

\section{References}

[1] Hurkmans CW, Cuijpers JP, Lagerwaard FJ, et al. Recommendations for implementing stereotactic radiotherapy in peripheral stage IA non-small cell lung cancer: report from the Quality Assurance Working Party of the randomised phase III ROSEL study. Radiat Oncol 2009:4:1.

[2] Fowler JF, Tome WA, Fenwick JD, Mehta MP. A challenge to traditional radiation oncology. Int J Radiat Oncol Biol Phys 2004;60:1241-56. 
[3] van Baardwijk A, Bosmans G, Bentzen SM, et al. Radiation dose prescription for non-small-cell lung cancer according to normal tissue dose constraints: an in silico clinical trial. Int J Radiat Oncol Biol Phys 2008;71:1103-10.

[4] van Baardwijk A, Wanders S, Boersma L, et al. Mature results of an individualized radiation dose prescription study based on normal tissue constraints in stages I to III non-small-cell lung cancer. J Clin Oncol 2010;28:1380-6.

[5] Chun FK, Karakiewicz PI, Briganti A, et al. Prostate cancer nomograms: an update. Eur Urol 2006;50:914-26 [discussion 926].

[6] Valdagni R, Rancati T, Fiorino C, et al. Development of a set of nomograms to predict acute lower gastrointestinal toxicity for prostate cancer 3D-CRT. Int J Radiat Oncol Biol Phys 2008;71:1065-73.

[7] Bradley JD, Hope A, El Naqa I, et al. A nomogram to predict radiation pneumonitis, derived from a combined analysis of RTOG 9311 and institutional data. Int J Radiat Oncol Biol Phys 2007;69:985-92.

[8] Dehing-Oberije C, Yu S, De Ruysscher D, et al. Development and external validation of prognostic model for 2-year survival of non-small-cell lung cancer patients treated with chemoradiotherapy. Int J Radiat Oncol Biol Phys 2009;74:355-62.

[9] Smith WP, Doctor J, Meyer J, Kalet IJ, Phillips MH. A decision aid for intensitymodulated radiation-therapy plan selection in prostate cancer based on a prognostic Bayesian network and a Markov model. Artif Intell Med 2009;46:119-30.

[10] Martel MK, Ten Haken RK, Hazuka MB, et al. Estimation of tumor control probability model parameters from 3-D dose distributions of non-small cell lung cancer patients. Lung Cancer 1999;24:31-7.

[11] Kwa SL, Lebesque JV, Theuws JC, et al. Radiation pneumonitis as a function of mean lung dose: an analysis of pooled data of 540 patients. Int J Radiat Oncol Biol Phys 1998;42:1-9.

[12] Bentzen SM. Theragnostic imaging for radiation oncology: dose-painting by numbers. Lancet Oncol 2005;6:112-7.

[13] Padhani AR, Krohn KA, Lewis JS, Alber M. Imaging oxygenation of human tumours. Eur Radiol 2007; 17:861-72.

[14] Alonzi R, Hoskin P. Functional imaging in clinical oncology: magnetic resonance imaging- and computerised tomography-based techniques. Clin Oncol (R Coll Radiol) 2006;18:555-70.

[15] Aerts HJ, van Baardwijk AA, Petit SF, et al. Identification of residual metabolicactive areas within individual NSCLC tumours using a pre-radiotherapy (18)fluorodeoxyglucose-PET-CT scan. Radiother Oncol 2009;91:386-92.

[16] Ling CC, Humm J, Larson S, et al. Towards multidimensional radiotherapy (MDCRT): biological imaging and biological conformality. Int J Radiat Oncol Biol Phys 2000;47:551-60.

[17] Malinen E, Sovik A, Hristov D, Bruland OS, Olsen DR. Adapting radiotherapy to hypoxic tumours. Phys Med Biol 2006;51:4903-21.

[18] Sovik A, Malinen E, Bruland OS, Bentzen SM, Olsen DR. Optimization of tumour control probability in hypoxic tumours by radiation dose redistribution: a modelling study. Phys Med Biol 2007;52:499-513.

[19] Alber M, Paulsen F, Eschmann SM, Machulla HJ. On biologically conformal boost dose optimization. Phys Med Biol 2003;48:N31-5.

[20] Thorwarth D, Eschmann SM, Paulsen F, Alber M. Hypoxia dose painting by numbers: a planning study. Int J Radiat Oncol Biol Phys 2007;68:291-300.

[21] Yang Y, Xing L. Towards biologically conformal radiation therapy (BCRT): selective IMRT dose escalation under the guidance of spatial biology distribution. Med Phys 2005;32:1473-84.

[22] Chao KS, Bosch WR, Mutic S, et al. A novel approach to overcome hypoxic tumor resistance: $\mathrm{Cu}$-ATSM-guided intensity-modulated radiation therapy. Int J Radiat Oncol Biol Phys 2001;49:1171-82.

[23] Petit SF, Aerts HJ, van Loon JG, et al. Metabolic control probability in tumour subvolumes or how to guide tumour dose redistribution in non-small cell lung cancer (NSCLC): an exploratory clinical study. Radiother Oncol 2009;91:393-8.

[24] Vaupel P, Kallinowski F, Okunieff P. Blood flow, oxygen and nutrient supply, and metabolic microenvironment of human tumors: a review. Cancer Res 1989;49:6449-65.

[25] Brizel DM, Sibley GS, Prosnitz LR, Scher RL, Dewhirst MW. Tumor hypoxia adversely affects the prognosis of carcinoma of the head and neck. Int J Radiat Oncol Biol Phys 1997;38:285-9.

[26] Magagnin MG, Koritzinsky M, Wouters BG. Patterns of tumor oxygenation and their influence on the cellular hypoxic response and hypoxia-directed therapies. Drug Resist Updat 2006;9:185-97.

[27] Wouters BG, Brown JM. Cells at intermediate oxygen levels can be more important than the "hypoxic fraction" in determining tumor response to fractionated radiotherapy. Radiat Res 1997;147:541-50.

[28] Petit SF, Dekker AL, Seigneuric R, et al. Intra-voxel heterogeneity influences the dose prescription for dose-painting with radiotherapy: a modelling study Phys Med Biol 2009;54:2179-96.

[29] Rasey JS, Grunbaum Z, Magee S, et al. Characterization of radiolabeled fluoromisonidazole as a probe for hypoxic cells. Radiat Res 1987;111:292-304.

[30] Bentzen L, Keiding S, Horsman MR, Gronroos T, Hansen SB, Overgaard J. Assessment of hypoxia in experimental mice tumours by [18F]fluoromisonidazole PET and $\mathrm{pO}_{2}$ electrode measurements. Influence of tumour volume and carbogen breathing. Acta Oncol 2002;41:304-12.

[31] Rajendran JG, Schwartz DL, O'Sullivan J, et al. Tumor hypoxia imaging with [F18]fluoromisonidazole positron emission tomography in head and neck cancer. Clin Cancer Res 2006;12:5435-41.

[32] Zimny M, Gagel B, Dimartino E, et al. FDG-a marker of tumour hypoxia? A comparison with [(18)F]fluoromisonidazole and pO (2)-polarography in metastatic head and neck cancer. Eur J Nucl Med Mol Imaging 2006:33:1426-31.

[33] Eschmann SM, Paulsen F, Reimold M, et al. Prognostic impact of hypoxia imaging with $18 \mathrm{~F}-$ misonidazole PET in non-small cell lung cancer and head and neck cancer before radiotherapy. J Nucl Med 2005;46:253-60.

[34] Laprie A, Catalaa I, Cassol E, et al. Proton magnetic resonance spectroscopic imaging in newly diagnosed glioblastoma: predictive value for the site of postradiotherapy relapse in a prospective longitudinal study. Int J Radiat Oncol Biol Phys 2008;70:773-81.

[35] Abramyuk A, Tokalov S, Zophel K, et al. Is pre-therapeutical FDG-PET/CT capable to detect high risk tumor subvolumes responsible for local failure in non-small cell lung cancer? Radiother Oncol 2009;91:399-404.

[36] Aerts HJ, Bosmans G, van Baardwijk AA, et al. Stability of 18F-deoxyglucose uptake locations within tumor during radiotherapy for NSCLC: a prospective study. Int J Radiat Oncol Biol Phys 2008;71:1402-7.

[37] Schutze C, Bergmann R, Yaromina A, et al. Effect of increase of radiation dose on local control relates to pre-treatment FDG uptake in FaDu tumours in nude mice. Radiother Oncol 2007;83:311-5.

[38] van Baardwijk A, Bosmans G, van Suylen RJ, et al. Correlation of intra-tumour heterogeneity on 18F-FDG PET with pathologic features in non-small cell lung cancer: a feasibility study. Radiother Oncol 2008;87:55-8

[39] Gillham C, Zips D, Ponisch F, et al. Additional PET/CT in week 5-6 of radiotherapy for patients with stage III non-small cell lung cancer as a means of dose escalation planning? Radiother Oncol 2008;88:335-41.

[40] Aerts HJ, Dubois L, Perk L, et al. Disparity between in vivo EGFR expression and 89Zr-labeled cetuximab uptake assessed with PET. J Nucl Med 2009;50:123-31.

[41] Muylle K, Vugts DJ, Meuleman N, et al. Diagnostic accuracy of 89Zr-rituximabPET/CT imaging in patients with relapsed CD20+ B-cell non-Hodgkin's lymphoma: comparison with 18FDG-PET. Eur J Nucl Med Mol Imaging 2009;36:OP424 [abstract].

[42] Grosu AL, Souvatzoglou M, Roper B, et al. Hypoxia imaging with FAZA-PET and theoretical considerations with regard to dose painting for individualization of radiotherapy in patients with head and neck cancer. Int J Radiat Oncol Biol Phys 2007;69:541-51.

[43] Chen GP, Ahunbay E, Schultz C, Li XA. Development of an inverse optimization package to plan nonuniform dose distributions based on spatially inhomogeneous radiosensitivity extracted from biological images. Med Phys 2007;34:1198-205.

[44] Rodrigues G, Lock M, D’Souza D, Yu E, Van Dyk J. Prediction of radiation pneumonitis by dose-volume histogram parameters in lung cancer - a systematic review. Radiother Oncol 2004;71:127-38.

[45] van Beek EJ, Hoffman EA. Functional imaging: CT and MRI. Clin Chest Med 2008;29:195-216. vii.

[46] Eichinger M, Tetzlaff R, Puderbach M, Woodhouse N, Kauczor HU. Proton magnetic resonance imaging for assessment of lung function and respiratory dynamics. Eur J Radiol 2007;64:329-34.

[47] Ireland $\mathrm{RH}$, Bragg $\mathrm{CM}$, McJury $\mathrm{M}$, et al. Feasibility of image registration and intensity-modulated radiotherapy planning with hyperpolarized helium-3 magnetic resonance imaging for non-small-cell lung cancer. Int J Radiat Oncol Biol Phys 2007;68:273-81.

[48] Simon BA. Non-invasive imaging of regional lung function using X-ray computed tomography. J Clin Monit Comput 2000;16:433-42.

[49] Guerrero T, Sanders K, Castillo E, et al. Dynamic ventilation imaging from fourdimensional computed tomography. Phys Med Biol 2006;51:777-91.

[50] Guerrero T, Sanders K, Noyola-Martinez J, et al. Quantification of regional ventilation from treatment planning CT. Int J Radiat Oncol Biol Phys 2005;62:630-4.

[51] Yaremko BP, Guerrero TM, Noyola-Martinez J, et al. Reduction of normal lung irradiation in locally advanced non-small-cell lung cancer patients, using ventilation images for functional avoidance. Int J Radiat Oncol Biol Phys 2007;68:562-71.

[52] Seppenwoolde Y, Muller SH, Theuws JC, et al. Radiation dose-effect relations and local recovery in perfusion for patients with non-small-cell lung cancer. Int J Radiat Oncol Biol Phys 2000;47:681-90.

[53] Marks LB, Spencer DP, Bentel GC, et al. The utility of SPECT lung perfusion scans in minimizing and assessing the physiologic consequences of thoracic irradiation. Int J Radiat Oncol Biol Phys 1993;26:659-68.

[54] Lavrenkov K, Christian JA, Partridge M, et al. A potential to reduce pulmonary toxicity: the use of perfusion SPECT with IMRT for functional lung avoidance in radiotherapy of non-small cell lung cancer. Radiother Oncol 2007;83:156-62.

[55] Seppenwoolde Y, Engelsman M, De Jaeger K, et al. Optimizing radiation treatment plans for lung cancer using lung perfusion information. Radiother Oncol 2002;63:165-77.

[56] McGuire SM, Marks LB, Yin FF, Das SK. A methodology for selecting the beam arrangement to reduce the intensity-modulated radiation therapy (IMRT) dose to the SPECT-defined functioning lung. Phys Med Biol 2010;55:403-16.

[57] Alavi A, Gupta N, Alberini JL, et al. Positron emission tomography imaging in nonmalignant thoracic disorders. Semin Nucl Med 2002;32:293-321.

[58] Hart JP, McCurdy MR, Ezhil M, et al. Radiation pneumonitis: correlation of toxicity with pulmonary metabolic radiation response. Int J Radiat Oncol Biol Phys 2008;71:967-71.

[59] De Ruysscher D, Houben A, Aerts HJ, et al. Increased (18)F-deoxyglucose uptake in the lung during the first weeks of radiotherapy is correlated with subsequent Radiation-Induced Lung Toxicity (RILT): a prospective pilot study. Radiother Oncol 2009;91:415-20. 
[60] Petit S, Elmpt v, Dehing-Oberije. 18F-fluorodeoxyglucose uptake patterns in the lung before radiotherapy identify areas that are more susceptible to radiation-induced lung toxicity in non-small cell lung cancer patients. Int J Radiat Oncol Biol Phys 2010; doi:10.1016/j.jirobp.2010.06.016.

[61] Sovik A, Malinen E, Skogmo HK, Bentzen SM, Bruland OS, Olsen DR. Radiotherapy adapted to spatial and temporal variability in tumor hypoxia. Int J Radiat Oncol Biol Phys 2007;68:1496-504.

[62] Vanderstraeten B, Duthoy W, De Gersem W, De Neve W, Thierens H. [18F]Fluoro-deoxy-glucose positron emission tomography ([18F]FDG-PET) voxel intensity-based intensity-modulated radiation therapy (IMRT) for head and neck cancer. Radiother Oncol 2006;79:249-58.

[63] Sovik A, Malinen E, Olsen DR. Strategies for biologic image-guided dose escalation: a review. Int J Radiat Oncol Biol Phys 2009;73:650-8.

[64] MacManus M, Nestle U, Rosenzweig KE, et al. Use of PET and PET/CT for radiation therapy planning: IAEA expert report 2006-2007. Radiother Oncol 2009;91:85-94.

[65] Shioyama Y, Jang SY, Liu HH, et al. Preserving functional lung using perfusion imaging and intensity-modulated radiation therapy for advanced-stage nonsmall cell lung cancer. Int J Radiat Oncol Biol Phys 2007;68:1349-58.

[66] Das S. A role for biological optimization within the current treatment planning paradigm. Med Phys 2009;36:4672-82.

[67] Das SK, Miften MM, Zhou S, et al. Feasibility of optimizing the dose distribution in lung tumors using fluorine-18-fluorodeoxyglucose positron emission tomography and single photon emission computed tomography guided dose prescriptions. Med Phys 2004;31:1452-61.

[68] Heath E, Unkelbach J, Oelfke U. Incorporating uncertainties in respiratory motion into 4D treatment plan optimization. Med Phys 2009;36:3059-71.

[69] Witte MG, van der Geer J, Schneider C, Lebesque JV, Alber M, van Herk M. IMRT optimization including random and systematic geometric errors based on the expectation of TCP and NTCP. Med Phys 2007;34:3544-55.

[70] van Elmpt W, McDermott L, Nijsten S, Wendling M, Lambin P, Mijnheer B. A literature review of electronic portal imaging for radiotherapy dosimetry. Radiother Oncol 2008;88:289-309.

[71] Nijsten SM, van Elmpt WJ, Mijnheer BJ, et al. Prediction of DVH parameter changes due to setup errors for breast cancer treatment based on 2D portal dosimetry. Med Phys 2009;36:83-94.

[72] McDermott LN, Wendling M, Sonke JJ, van Herk M, Mijnheer BJ. Replacing pretreatment verification with in vivo EPID dosimetry for prostate IMRT. Int J Radiat Oncol Biol Phys 2007;67:1568-77.

[73] Renner WD. 3D dose reconstruction to insure correct external beam treatment of patients. Med Dosim 2007;32:157-65.

[74] Van Esch A, Depuydt T, Huyskens DP. The use of an aSi-based EPID for routine absolute dosimetric pre-treatment verification of dynamic IMRT fields. Radiother Oncol 2004;71:223-34.

[75] Wendling M, McDermott LN, Mans A, Sonke JJ, van Herk M, Mijnheer BJ. A simple backprojection algorithm for 3D in vivo EPID dosimetry of IMRT treatments. Med Phys 2009;36:3310-21.
[76] Petit SF, van Elmpt WJ, Lambin P, Dekker AL. Dose recalculation in megavoltage cone-beam CT for treatment evaluation: removal of cupping and truncation artefacts in scans of the thorax and abdomen. Radiother Oncol 2010;94:359-66.

[77] van Elmpt W, Petit S, De Ruysscher D, Lambin P, Dekker A. 3D dose delivery verification using repeated cone-beam imaging and EPID dosimetry for stereotactic body radiotherapy of non-small cell lung cancer. Radiother Oncol 2010;94:188-94.

[78] Chen J, Morin O, Aubin M, Bucci MK, Chuang CF, Pouliot J. Dose-guided radiation therapy with megavoltage cone-beam CT. Br J Radiol 2006;79 Spec. No. 1:S87-98.

[79] Partridge M, Ebert M, Hesse BM. IMRT verification by three-dimensional dose reconstruction from portal beam measurements. Med Phys 2002;29:1847-58.

[80] McDermott LN, Wendling M, Nijkamp J, et al. 3D in vivo dose verification of entire hypo-fractionated IMRT treatments using an EPID and cone-beam CT. Radiother Oncol 2008;86:35-42.

[81] van Zijtveld M, Dirkx M, Heijmen B. Correction of conebeam CT values using a planning CT for derivation of the "dose of the day". Radiother Oncol 2007;85:195-200.

[82] van Elmpt W, Nijsten S, Petit S, Mijnheer B, Lambin P, Dekker A. 3D in vivo dosimetry using megavoltage cone-beam CT and EPID dosimetry. Int J Radiat Oncol Biol Phys 2009;73:1580-7.

[83] Bosmans G, van Baardwijk A, Dekker A, et al. Intra-patient variability of tumor volume and tumor motion during conventionally fractionated radiotherapy for locally advanced non-small-cell lung cancer: a prospective clinical study. Int J Radiat Oncol Biol Phys 2006;66:748-53.

[84] Sonke JJ, Lebesque J, van Herk M. Variability of four-dimensional computed tomography patient models. Int J Radiat Oncol Biol Phys 2008;70:590-8.

[85] van Elmpt W, Öllers M, van Herwijnen H, et al. Volume or position changes of the primary lung tumor during (chemo-)radiotherapy cannot be used as a surrogate for the mediastinal lymph node changes: the case for optimal mediastinal lymph node imaging during radiotherapy. Int J Radiat Oncol Biol Phys; doi:10.1016/j.ijrobp.2009.10.059.

[86] Verellen D, De Ridder M, Storme G. A (short) history of image-guided radiotherapy. Radiother Oncol 2008;86:4-13.

[87] Woodford C, Yartsev S, Dar AR, Bauman G, Van Dyk J. Adaptive radiotherapy planning on decreasing gross tumor volumes as seen on megavoltage computed tomography images. Int J Radiat Oncol Biol Phys 2007;69:1316-22.

[88] Harsolia A, Hugo GD, Kestin LL, Grills IS, Yan D. Dosimetric advantages of fourdimensional adaptive image-guided radiotherapy for lung tumors using online cone-beam computed tomography. Int J Radiat Oncol Biol Phys 2008;70:582-9.

[89] Ahunbay EE, Peng C, Chen GP, et al. An on-line replanning scheme for interfractional variations. Med Phys 2008;35:3607-15. 